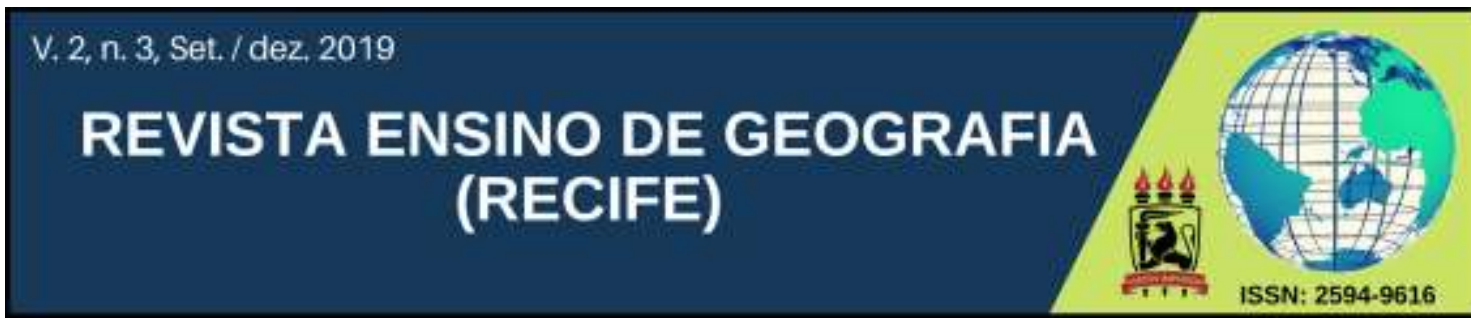

\title{
OS DESAFIOS DA PRÁTICA EDUCATIVA DO PROFESSOR DE GEOGRAFIA NO DESENVOLVIMENTO DO RACIOCÍNIO GEOGRÁFICO
}

\author{
Daniel Rodrigues Silva Luz Neto \\ Mestre em Geografia, Universidade de Brasília (UnB) \\ danieltabuleiro1@gmail.com \\ ORCID Id: http://orcid.org/0000-0002-6326-4906
}

Artigo recebido em 20/11/2019 e aceito em 22/12/2019

\begin{abstract}
RESUMO:
O contexto de mundo contemporâneo é caracterizado por muitos atributos, dentre eles, o processo de globalização econômica. Apesar desse processo não ser recente, as mudanças decorridas na segunda metade do século XX têm implicado na aceleração e intensificação das transformações socioespaciais. Assim, as práticas espaciais dos sujeitos têm se tornado cada vez mais complexas, pois se amplia a dificuldade de compreensão e de atuação. Nesse sentido, reforça-se a importância do ensino de Geografia na interpretação de tais práticas pelo desenvolvimento do raciocínio geográfico junto ao aluno. Contudo, tal desenvolvimento perpassa por desafios. Diante disso, este trabalho objetiva-se analisar alguns desafios para o desenvolvimento do raciocínio na prática educativa do professor de Geografia na educação básica. Para tanto, utilizou-se a metodologia qualitativa, tanto na produção das informações bibliográficas como nas análises dos resultados. Os resultados mostraram haver muitos desafios para o desenvolvimento do raciocínio geográfico, dentre eles, destacou-se as influências das imposições de políticas para educação de cunho neoliberal, as condições físicas das escolas, bem como a formação de professores de Geografia.
\end{abstract}

Palavras-chave: Cognição; desafios; ensino; geografia; raciocínio.

\section{THE CHALLENGES OF THE EDUCATIONAL PRACTICE OF THE GEOGRAPHIC TEACHER IN THE DEVELOPMENT OF THE GEOGRAPHICAL REASONING}

\begin{abstract}
:
The contemporary world context is characterized by many attributes, including the process of economic globalization. Although this process is not recent, the changes that occurred in the second half of the twentieth century have led to the acceleration and intensification of socio-spatial transformations. Thus, the spatial practices of the subjects have become increasingly complex, as the difficulty of understanding and acting increases. In this sense, the importance of teaching geography in the interpretation of such practices is reinforced by the development of geographic reasoning with the student. However, such development faces challenges. Given this, this paper aims to analyze some challenges for the development of reasoning in the educational practice of the teacher of geography in basic education. For this, the qualitative methodology was used, both in the production of bibliographic information and in the analysis of the results. The results showed that there are many challenges for the development of geographical reasoning, among them the influences of the impositions of policies for neoliberal education, the physical conditions of the schools, as well as the formation of Geography teachers.
\end{abstract}

Keywords: Cognition; challenges; teaching; geography; reasoning. 


\section{INTRODUÇÃO}

Um dos principais atributos do contexto de mundo contemporâneo é o processo de globalização da economia. Apesar desse processo não ser recente, sem dúvida, as mudanças decorridas na segunda metade do século XX têm implicado na aceleração e intensificação das transformações nas configurações espaciais. Dessa forma, as práticas espaciais dos sujeitos tornam-se cada vez mais complexas, aumentando a dificuldade de compreensão. Sendo assim, o ensino de Geografia pode contribuir para a interpretação e atuação de forma críticoreflexiva diante desses processos socioespaciais pelo desenvolvimento do raciocínio geográfico.

A Base Nacional Comum Curricular (BNCC) e pesquisadores do campo da Geografia Escolar afirmam que a Geografia enquanto componente escolar no processo de escolarização tem a função de formar os alunos por meio do desenvolvimento do raciocínio geográfico. Este, por sua vez, é um processo cognitivo peculiar da Geografia, pois outras ciências também se preocupam com o espaço - Psicologia, Matemática, Física, para citar algumas - mas não na dimensão da Geografia, que envolve um olhar com objetivos diferentes da abordagem de outras ciências sobre o espaço, por utilizar fundamentos teórico-metodológicos próprios de um saber geográfico. Dessa forma, o raciocínio geográfico é constituído por conceitos como espaço, território, paisagem, lugar, região e princípios lógicos, como localização, delimitação, extensão, conexão, rede, extensão, distribuição, posição, arranjo, dentre outros.

$\mathrm{O}$ interesse para pesquisar desafios para o desenvolvimento do raciocínio geográfico emergiu perante a atuação docente enquanto professor da Educação Básica. Assim, este professor-pesquisador realizou levantamentos teóricos e análise sobre alguns desses desafios que mais se apresentam na sua prática educativa. Dentre os desafios, discute-se três, por terem sido os mais recorrentes nos levantamentos teóricos realizados nesta pesquisa. Dessa forma, primeiro explora-se o cenário atual de globalização da economia, que tem como política orientadora o neoliberalismo, principalmente a partir da década de 1990, o qual tem influenciado em vários setores, inclusive na educação por meio da tentativa de diluição de algumas disciplinas promotoras de raciocínio crítico, como a Geografia. No segundo, explorase a situação da formação de professores, pois ainda no Brasil há muitos problemas que acarretam em lacunas para a promoção de práticas educativas mais crítico-reflexivas. Terceiro, problemas nas infraestruturas das instituições, como faltas de salas, ausência de manutenção. 
Dado o exposto, diante do contexto de mundo globalizado, dos desafios enumerados para uma prática educativa, para promover o desenvolvimento do raciocínio geográfico como um instrumento psicológico, para os alunos interpretarem suas práticas espaciais, questionase: como o professor pode desenvolver o raciocínio geográfico diante dos desafios apresentados na prática educativa?

Sendo assim, o objetivo deste trabalho é analisar os desafios para o desenvolvimento do raciocínio geográfico na prática educativa do professor de Geografia. Para isso, utiliza-se a metodologia qualitativa, tanto na produção das informações bibliográficas como nas análises dos resultados. Na produção e discussão dos resultados do trabalho, fundamentou-se em algumas categorias, como: contexto de mundo global - em Harvey (2014; 2006) e Santos (2008); Geografia Escolar - em Cavalcanti (2013; 2012; 2010), Pontuschka ( 2013) e Kaercher (2010); projetos neoliberais - em Alexander (2012; 2005) e Saviani (2018); condições das estruturais das escolas públicas - em Cavalcanti (2010), Pireis (2013) e Silva (2016); e, por fim, formação de professore de Geografia - em Cunha (2010), Pimenta (1999) e Shulman (2014).

\section{O CONTEXTO DE MUNDO E O ENSINO DE GEOGRAFIA}

O mundo contemporâneo é marcado por diversas características, dentre elas, as provocadas pela globalização econômica, que é um processo que tem influenciado vários ramos da sociedade, inclusive o ramo formativo. Tal influência decorre porque as ações dos atores hegemônicos do capitalismo têm promovido ações para a inserção da educação como ativo do mercado, tanto no que diz respeito a torna-la uma mercadoria como no processo de formação de mão de obra barata e sem criticidade.

Para Harvey (2006, p. 99) “[...] a globalização é sem dúvida o resultado de uma cruzada política empreendida pelos Estados Unidos (...) com alguns notáveis aliados, como a Grã-Bretanha no período thatcherismo". Nesse sentido, o termo globalização nada mais seria do que uma ideologia das revistas do mercado financeiro que tem como propósitos alienar os territórios e inseri-los na competitividade neoliberal sob a ótica desses atores hegemônicos que fazem parte do centro do sistema capitalista de produção. Essas novas políticas competitivas visam à intervenção flexível dos governos, em que o mercado é colocado como regulador pelos teóricos que defendem essa ideia de economia global.

Hoje, vivencia-se um contexto de mundo global em que se permite visualizar a noção de totalidade empírica. Esse período, por sua vez, é uma síntese de eventos que ocorrem no 
tempo e no espaço. Assim sendo, a cada momento muda-se concomitantemente o tempo, o espaço e o mundo. Contudo, o espaço depende muito da evolução dos meios de transportes e de comunicações na construção do espaço-tempo social. Dito isso, os sistemas técnicos atuais são mundiais, mesmo que sua distribuição seja, como antes, desigual, e o seu uso pela sociedade também seja, como antes, de maneira hierarquizada. Por isso, a ideia de mundo globalizado foi, indubitavelmente, proporcionada pela unicidade técnica, a qual levou à unificação do espaço em termos globais (SANTOS, 2008).

O projeto de mundo globalizado pós-guerra, certamente, ganhou novos contornos, em especial, no que diz respeito ao fator localização dos eventos. Sendo assim, os atores hegemônicos selecionaram os territórios mais dinâmicos e deixaram os que têm menos dinamismo com os atores não hegemônicos (SANTOS, 2015). Em concordância com Santos (2015), constata-se que as mudanças emergidas após a década de 1970 são oriundas da tentativa de contornar as crises inerentes ao modelo produtivo vigente na época, baseado na concepção fordista. Essa concepção fordista a qual, apesar de estar dentro da lógica contraditória inerente ao sistema capitalista, tinha no Estado de bem-estar formas de amenizar paliativamente as crises socioeconômicas.

A globalização econômica promovida pelos atores hegemônicos tem promovido expropriação e alienação em escala planetária, mas, por outro lado, pode apresentar-se também como possibilidade de lutas sociais por meio da apropriação dos instrumentos técnicos pelos atores contra-hegemônicos. Nesse sentido, os avanços globais, principalmente as novas técnicas, não devem ser ignorados, mas incorporados na luta por uma sociedade justa e emancipada (SANTOS 2015).

No Brasil, tais contradições da globalização capitalista têm se dado fortemente com a aliança ao fator político, como explicita Saviani (2018), quer "o golpe de estado em 2016" alia-se aos interesses do capital. Isso porque, a partir desse contexto até a presente data, em 2019, houve a diminuição de direitos sociais como a reforma da previdência que aumentou o tempo de contribuição do trabalhador, como a tentativa de privatização de serviços públicos essenciais para as classes populares principalmente; e de ataques perversos a escola e universidade pública, que é um dos ramos essenciais para a diminuição das desigualdades sociais. Tudo isso para atender às taxas de lucratividade do capital, em demasia, dos atores oriundos dos Estados Unidos.

Dado o exposto, o ensino de Geografia pode cumprir um papel importante nesse contexto, pois os professores de Geografia podem desenvolver a capacidade cognitiva dos 
alunos de interpretarem as contradições espaciais e de visualizarem possibilidades de transformação da realidade por meio do raciocínio geográfico. Para isso, os docentes devem se orientar no processo de ensino-aprendizagem; nos fundamentos teórico-metodológico da Geografia como os conceitos de espaço, território, lugar, paisagem, região; e nos princípios lógicos como localização, delimitação, rede, escala, arranjo, conexão, dentre outros.

Portanto, diante desse contexto de mundo globalizado, a Geografia Escolar pode instrumentalizar os alunos a interpretarem e atuarem nas práticas espaciais de forma críticoreflexiva por meio do desenvolvimento do raciocínio geográfico. Este pode ser mobilizado pelos estudantes para interpretarem e, consequentemente, desenvolverem atitudes emancipatórias. Assim, na próxima seção, discutir-se-á o que é Geografia Escolar, qual a diferença entre a realizada na universidade, qual o papel do professor e como o ensino de geografia pode ser importante para os alunos.

\section{GEOGRAFIA ESCOLAR: entre campos de saberes e de atuação do professor de Geografia}

Há no cotidiano escolar e na academia uma diferenciação das formulações e concepções teóricas sobre a definição (origem, fundamentos, referências, características, especificidades) da Geografia Escolar, que se inscreve num debate mais amplo acerca da natureza dos saberes escolares. Algumas dessas dúvidas se remetem aos questionamentos: Geografia Escolar é a reprodução da Geografia acadêmica? Geografia Escolar é somente uma exigência das instituições educacionais para complementar a carga horária exigida no currículo pelo Ministério da Educação? De acordo com Cavalcanti (2013, p. 9):

\footnotetext{
A relação entre uma ciência e matéria é complexa; ambas formam uma unidade, mas não são idênticas. A ciência geográfica constitui-se de teorias, conceitos e métodos referentes à problemática de seu objeto de investigação. A matéria de ensino Geografia corresponde ao conjunto de saberes dessa ciência.
}

Assim sendo, a Geografia Escolar não é a simplificação da Geografia acadêmica como é percebida no senso comum. Essa Geografia Escolar é construída pelo professor de Geografia em sala de aula, por meio de diferentes procedimentos teórico-metodológicos e mediados por: teorias, metodologias, estratégias dos docentes e de seleções de conteúdos curriculares para serem trabalhados na atuação docente no desenvolvimento do raciocínio geográfico.

Dado o exposto, concorda-se com Pontuschka (2013, p. 447) quando ela diz que "a Geografia escolar não é a simplificação do saber acadêmico. Há uma ideia preconceituosa 
segundo a qual aqueles níveis de ensino (fundamental e médio) devem apenas simplificar e reproduzir os conteúdos produzidos na acadêmica".

Além do mais, partilha-se da visão da autora quando ela ressalta a existência de certa visão "preconceituosa" quando se remete à atuação do professor de Geografia na escola básica, pois há uma supervalorização da Geografia acadêmica em detrimento da que é exercida na escola. Isso porque a própria academia e o senso comum julgam que para ensinar Geografia é necessário somente saber suas teorias e seus métodos sem correlaciona-los com o pedagógico. Esse pensamento se dá pelo fato de a Educação Geográfica envolver múltiplos saberes para além do geográfico.

Na perspectiva equivocada sobre o ensino de Geografia na Educação Básica, julga-se um bom professor de Geografia aquele que tem domínio teórico dessa ciência. Contudo, os estudos e as reflexões do campo da Geografia Escolar mostram que não é somente isso que configura uma atuação docente neste nível educacional, pois o ensino é uma atividade complexa e dinâmica, a qual envolve múltiplos fatores no exercício da prática educativa no cotidiano escolar. Dessa forma, as referências do ensino de Geografia nos dias atuais, de acordo com Cavalcanti (2012), devem considerar não só os aspectos dos elementos da escola, do professor e da comunidade escolar, mas explorar a lógica dialética estrutural do global, a qual traz consigo fatores que influenciam o contexto educacional.

Não obstante, o novo cenário para a atuação do professor de Geografia apresenta dois vieses: ou se fecham tradicionalmente ou buscam um caminho político de mudança social dos sujeitos no processo de ensino por intermédio de novas perspectivas didático-pedagógicas para o processo de ensino-aprendizagem. Dessa forma, Cavalcanti (2010, p. 01) reforça esse posicionamento quando diz que:

\footnotetext{
Em razão das inúmeras dificuldades que enfrentam no trabalho, alguns professores se sentem inseguros e se fecham em uma atitude conservadora: optam por manter os rituais rotineiros e repetitivos da sala de aula, desistindo de experimentar caminhos novos. Outros pautam seu trabalho pelo desejo permanente de promover a aprendizagem significativa dos conteúdos que ensinam, envolvendo seus alunos e articulando intencionalmente seus projetos profissionais a projetos sociais mais amplos.
}

Dito isso, compartilha-se da ideia de Cavalcanti (2010), pois, diante do contexto de mundo e da complexidade das práticas educativas, é importante reconhecer as várias nuanças desafiantes, mas, concomitantemente, não se pode jogar a culpa de todos os problemas educacionais somente aos professores. Tal argumento se reverbera porque existem diversos 
fatores que influenciam no processo de ensino-aprendizagem, sejam eles de ordem local ou global. Além disso, ainda há manutenção do modelo de escola do Século XIX, no qual os alunos são postos na organização fabril, isso se evidencia com enfileiramentos, cumprimento de ordens e de horários rígidos e tratamento com os alunos como se fossem depósitos de informações. Tal realidade não condiz com as novas demandas dos escolares, bem como das particularidades pessoais e profissionais.

Em primeiro lugar, as particularidades de ordem pessoal na atuação docente devem também ser consideradas, como: problemas fisiológicos, dificuldade de se expressar, dificuldade nas relações humanas. E, segundo, as questões de dimensões profissionais, como o tipo de instituição de atuação docente, particular ou pública; tipo de relação com as instituições, temporárias ou efetivas; e do tipo de respaldo que tem da gestão escolar e pedagógica na realização tanto de suas atribuições quanto da autonomia que possam contribuir no desenvolvimento cognitivo dos alunos pela aprendizagem.

Para Lacoste (2012), um dos problemas para que a Geografia tenha negado a prática e a reprodução do modelo de Geografia sistematizada como ciência ainda no final do século XIX são os modelos pautados em métodos e em práticas da época, os quais têm prejudicado os processos práticos e, portanto, até o crescimento da Geografia enquanto uma ciência social, bem como uma disciplina escolar. Diante disso, a formação inicial, de acordo com Kaercher (2010, p.177), deveria ser levada mais a sério, tendo em vista que o docente é o maior influenciador do aluno. No entanto, o autor constatou que o ensino de Geografia na universidade continua ainda tradicional e fragmentador da realidade do discente. E, por isso, sem significação e criticidade, é repassado para os alunos por meio da simples descrição dos fatos socioambientais.

Já para Khaoule (2013), a formação baseada no professor reflexivo é uma possibilidade para a transformação do ensino, pois pode possibilitar aos professores a reflexão das próprias práticas educativas em que possam reconhecer seu papel como protagonista na transformação da vida dos educandos pela escolarização.

A educação escolar não é a panaceia para todos os problemas dos sujeitos, mas exerce uma importante função para que as sociedades se desenvolvam em uma concepção de humanização, em que o ensino é um desses instrumentos por meio da promoção da aprendizagem. Libâneo $(1994$, p. 16) ratifica tal relevância, visto que "[...] a prática educativa é um fenômeno social e universal, sendo uma atividade humana necessária à existência e ao funcionamento de todas as sociedades". 
Por sua vez, Freire (2015) diz que ninguém pode estar nesse mundo de maneira neutra. Sendo assim, deve-se atuar de maneira interventiva na perspectiva de transformação como sujeitos ativos no percurso das mudanças históricas da sociedade. De acordo com esse pensamento, o professor tem um papel primordial para fazer uma prática educativa, estabelecendo correlações entre as escalas geográfica, históricas, tendo-se como princípio tornar os educandos sujeitos críticos e atuantes da realidade destes.

No âmbito da Educação Básica, a Base Nacional Comum Curricular (BNCC) incorporou em seu documento, como um dos objetivos da Educação Geográfica, o desenvolvimento do raciocínio geográfico. De acordo com a BNCC, "para fazer a leitura de mundo em que se vive com base em aprendizagem em Geografia, os alunos precisam ser estimulados a pensar espacialmente, desenvolvendo o raciocínio geográfico" (BRASIL, 2017, p. 357). Esse documento traz algumas orientações a serem elencadas no desenvolver do raciocínio geográfico, tanto com os princípios lógicos quanto com os conceitos fundantes da Geografia.

Dado o contexto, o desenvolvimento do raciocínio geográfico se faz necessário para possibilitar ao aluno a interpretação das práticas espaciais de forma crítico-reflexiva. No entanto, por outro lado, as políticas de cunho neoliberal têm buscado impor a formação escolar mais técnica, para garantir a reprodução do capital inserindo os sujeitos tanto como mão de obra barata como criando necessidades para que eles possam acreditar no consumo como o atendimento de suas necessidades e de seus sonhos. Dessa forma, o raciocínio geográfico perpassa por desafios e possibilidades (GAUDIO et al, 2017). Assim, na próxima seção serão discutidas algumas reflexões sobre como as implicações dos projetos neoliberais desafiam o desenvolvimento do raciocínio geográfico.

\section{PROJETOS NEOLIBERAIS: o direcionamento das políticas públicas pós-década de 1990}

Os desafios no desenvolvimento do raciocínio geográfico com o aluno da Educação Básica não são homogêneos, por isso, podem aparecer em algumas instituições educacionais e em outras não. Ademais, há também muitas experiências exitosas na prática educativa em instituições públicas, algumas instituições são equipadas com aparatos tecnológicos, outras têm excelentes estruturas físicas e outras têm boa gestão escolar. Contudo, não se pode negar os percalços: práticas pedagógicas tradicionais liberais, problemas na formação dos professores de Geografia, péssimas condições de infraestruturas em algumas instituições, 
carga horária excessiva dos docentes e a falta de perspectiva de melhoria na carreira (PIRES, 2012; TARDIF, 2012).

Contudo, historicamente, o ensino de Geografia vem passando por longos desafios desde sua regulamentação na educação escolar no Brasil. Os avanços foram a incorporação da Geografia nas universidades; e o retrocesso, logo adiante, foi a incorporação das licenciaturas curtas no período militar. Em seguida, depois da Ditadura, surgiu outro movimento, agora, sendo o capitalismo neoliberal um desafio para o desenvolvimento do raciocínio geográfico crítico-reflexivo, favorável a um ensino tecnicista para atender em demasia ao mercado de trabalho.

As políticas públicas sobre o viés neoliberal deixaram de lado o desenvolvimento do raciocínio crítico-reflexivo a favor da formação acrítica, que mascara as mazelas sociais e visa à adaptação dos sujeitos à realidade dos anseios dos atores centrais do mundo capitalista. Dessa forma, as ações pedagógicas são orientadas para a socialização em detrimento do conhecimento. E com isso foge de um dos princípios da educação escolar, que é o de formação integral do sujeito para atuar em sociedade de forma crítico-reflexiva (PONTUSCHKA, 2013).

Os analistas globais que tratam de educação ligada ao contexto neoliberal de mundo global têm uma percepção distante da complexidade da sala de aula. Assim, seus pesquisadores trazem resultados desconexos com a realidade vivida em cada país. Nesse sentido, as políticas implementadas por esses atores para a educação, em geral, desviam da função primordial de formação não só para o mundo do trabalho, mas, sobretudo, para o desenvolvimento dos sujeitos como seres humanos para viverem em sociedade. Além disso, a questão de candidaturas a cargos públicos, que, em virtude da necessidade de serem eleitos, faz com que os políticos introduzam modelos educacionais mais voltados para atender aos desejos dos atores hegemônicos credores de suas campanhas (ALEXANDER, 2012). Dito isso, os projetos para educação, principalmente nos países mais pobres, acabam sendo de governo e não efetivamente de estado para atingir realmente as necessidades sociais.

A título de exemplificação dos parâmetros usados pelos atores globais que influenciam em políticas públicas para a educação escolar, tem-se, nos últimos anos, reconhecido o "sucesso" do sistema educacional da Finlândia. No entanto, há alguns elementos que devem ser questionados e/ou revistos, uma vez que há interesses implícitos destes financiamentos por parte das grandes corporações financeiras globais. Diante desse contexto global, Alexander (2012) faz o seguinte questionamento: será que o modelo adotado 
pelos finlandeses não tem sido influenciado pelo movimento global da reforma educativa iniciada nos Estados Unidos e na Inglaterra, espalhada com a ajuda financeira dos grandes organismos financeiros e das empresas globais a partir da década de 1990? Em concordância com o autor, essas políticas têm se espalhado pelo mundo de forma rápida como uma espécie de vírus.

Alexander (2005) constata em seus estudos sobre vários países, como Estados Unidos, Inglaterra, dentre outros, que o movimento global pela reforma educativa está voltado para o mundo dos negócios em detrimento da formação integral dos estudantes. Ele partiu da premissa que não há neutralidade nas ações políticas, dessa forma, como essas reformas neoliberais são financiadas pelos grandes atores globais do capitalismo, existem interesses por detrás dessas tentativas de reformas globais. Para isso, tais reformas educacionais globais são impostas por meio da padronização do ensino, do foco em habilidades elementares e de uma pedagogia prescritiva.

Sendo assim, o objetivo de tais tentativas de financiamento e de efetuações de reformas é de tentarem garantir a reprodução global do capital por meio da formação de pessoas para o mercado e de inserir valores relativos aos interesses do mundo corporativo em escala global. Nesses moldes de reformas educacionais globais, emerge como fundamentação ideológica para ser incorporada à educação escolar a concepções de empreendedorismo, como formação para o sucesso dos alunos no mundo globalizado. Os resultados disso tudo são a diminuição da autonomia dos professores em realizarem estratégias pedagógicas em prol da construção dos conhecimentos em suas aulas e o foco no empreendedorismo individual em detrimento da formação global dos sujeitos.

Nesse eixo, transfere-se a responsabilidade pelo insucesso escolar tanto para os professores em escolas públicas como para os alunos. Sendo assim, essas concepções têm respingado no Brasil com muita força a partir da publicação da lei 13.415, da reforma do Ensino do Médio em vigor desde 2017. Essa lei direciona a educação pública para o ensino técnico em prejuízo à formação integral do aluno, pois somente as disciplinas de Língua Portuguesa e Matemática passam a ser obrigatórias, sendo as demais diluídas em itinerários formativos, como é o caso da Geografia (GAUDIO et al, 2017).

Para se tentar impor os anseios do capital, emergiu-se também a ideia de "Escola Sem Partido" na qual os professores em escolas públicas são considerados culpados por serem doutrinadores no sentido de não estimular os alunos para "vencer" na vida (SAVIANI, 2018). Outro eixo da transferência do insucesso escolar é de que os alunos são culpados pelo seu 
fracasso porque não querem nada com a vida, pois, nesta ótica do empreendedorismo individual, as condições são postas para todos. Desse ponto de vista, só não consegue nada quem não tem interesse de crescimento individual em negação às condições históricas, culturais, cognitivas e psicossociais dos sujeitos.

Apesar do contexto de mudanças promovido pelo movimento global de reformas educacionais, a Finlândia é peculiar porque seus currículos direcionam para dois elementos centrais que eles não abrem mão: equidade e qualidade. Nesse sentido, na Finlândia não tem tido exames nacionais para avaliar os seus docentes de forma classificatória; valorizam e confiam em seus professores; e, além disso, possibilitam para os educadores uma formação sólida antes de darem a autonomia (ALEXANDER, 2012).

Retomando-se ao questionamento acima de Alexander (2005) sobre a Finlândia, os projetos globais possivelmente influenciam ou poderão influenciar tal sistema educacional, pois eles estão atuando fortemente na mídia, nos grandes eventos globais, nacionais e até mesmos locais. Portanto, os encontros são financiados pelos organismos internacionais que geram as diretrizes impostas aos países mais pobres. No entanto, a sustentação do sistema finlandês depende também de fatores internos de resistências que estão ocorrendo na manutenção do princípio de equidade e de qualidade na educação.

Os direcionamentos do debate destas políticas neoliberais são no sentido de que, com o financiamento, viesse o pacote de medidas a serem adotados pela educação escolar no Brasil, como: universalização do ensino, educação a distância, inclusão, dentre outros. Contudo, essas medidas que a priori pareciam boas podem prejudicar o ensino de qualidade para todos. Isso porque direcionaram a escola para a inclusão e o acolhimento dos educandos, mas privando-a de uma educação também focada "no conhecimento poderoso" para servir aos escolares (PONTUSCHKA, 2013). No âmbito da Educação Superior, as ações neoliberais também vêm sendo realizadas por meio da difamação das universidades públicas, por exemplo, a ideia de "balbúrdia" sendo relacionada às ações docentes-discentes dentro das instituições, que visam desqualificar para defender a privatização. Assim, a título de exemplificação, em 2019, o Ministério da Educação (MEC) do Brasil apresentou o projeto Future-se como proposta de autonomia financeira das universidades, as quais aliam-se a esse projeto global neoliberal de atender aos atores do capitalismo hegemônico, submetendo a educação brasileira como um dos ativos do mercado global.

No âmbito da Educação Básica, afinal para que serve a escola? Em primeiro lugar cabe ressaltar que sem as escolas cada sociedade teria que começar do zero sua organização 
no espaço geográfico. No entanto, ela serve a propósitos antagônicos; nesse sentido, Young (2007) diz que a escola serve para atender tanto aos propósitos das classes sociais hegemônicas quanto das menos desfavorecidas socialmente. Em segundo lugar, cumprir com a demanda dos "conhecimentos dos poderosos" que é a garantia da manutenção do status quo por meio da apropriação dos conhecimentos pelas classes hegemônicas que os utilizam para se manterem enquanto classe dominante. E, em terceiro, para propagar o "conhecimento poderoso", o qual pode ser utilizado pelos sujeitos das classes não hegemônicas como instrumento psicológico de resistência às contradições sociais deparadas na vida cotidiana dos sujeitos (YOUNG, 2007).

Diante da explicitação da função da escola e dos conflitos políticos entre os atores, ressalta-se que com a escola pública brasileira não é diferente, pois historicamente ela passa por essa contradição, principalmente após-década de 1990, já que há uma intensificação dessa dualidade. Dessa forma, as ações são direcionadas para a prevalência do "conhecimento dos poderosos" em detrimento do "conhecimento poderoso". Assim, tem-se tentado realizar ações para a manutenção de escola do acolhimento para os pobres e do conhecimento para os ricos.

Nesses moldes citados, o desejo dos defensores dos "conhecimentos dos poderosos" é que, enquanto a escola pública oferta uma educação de acolhimento à classe pobre, as escolas particulares continuem nos moldes de ensinar os conhecimentos escolares. Diante disso, a consequência de tal concepção é de promover a manutenção do apartheid da educação formal, uma vez que dificultava ainda mais o acesso dos estudantes das classes menos favorecidas às universidades públicas, aos concursos e a uma formação cidadã críticoreflexiva.

Logo, cabe aos docentes o conhecimento de tais premissas das situações contextuais e da função do conhecimento para a prática social dos sujeitos para firmar um compromisso de continuar o papel de resistência por meio de suas estratégias pedagógicas para o desenvolvimento dos alunos pelo "conhecimento poderoso". E, no ensino de Geografia, desenvolver junto ao aluno o raciocínio geográfico para que este possa interpretar e atuar nas práticas espaciais tanto para acessar aos bens produzidos pela humanidade como de buscar a equidade social no acesso a tais condições necessárias à dignidade humana.

Outro fator que também pode ser um desafio para os docentes desenvolverem o raciocínio geográfico é a condição estrutural das escolas, que será discutido como tal condição dificulta a prática docente e como o professor pode lidar com isso. 


\section{AS CONDIÇÕES ESTRUTURAIS DAS ESCOLAS BRASILEIRAS}

Os problemas de estrutura física das instituições escolares no Brasil constituem também em desafios para o desenvolvimento do raciocínio geográfico, como falta de salas de aulas, ausência de instalação de rede de energia elétrica, estruturas que não suportam se inserir novos equipamentos, ausência de laboratórios, para citar alguns exemplos. Porém, Cavalcanti (2010) afirma que o professor pode se defrontar com esses percalços não em todas as escolas, mas em algumas. Diante disso, concorda-se com a autora que é preciso que os professores reconheçam a existência desses problemas e canalizem forças, por meio de lutas coletivas com os grupos sociais e seus pares para transformar a situação.

Pires (2013) realizou uma análise de práticas pedagógicas de professores de Geografia em cinco escolas públicas no município de Morrinhos, Goiás, em sua pesquisa de mestrado. Nesta pesquisa os professores relataram que um dos desafios da prática pedagógica é a condição estrutural das escolas. Eles enumeraram alguns desses desafios, como: a falta de laboratórios, a falta de salas de aulas bem ventiladas, a ausência de espaços esportivos e recreativos, dentre outros. Contudo, Pires (2013) reforça a ideia dizendo que esses elementos estruturais não são os únicos fatores determinantes que prejudicam nas estratégias pedagógicas, mas influenciam a prática educativa dos professores de Geografia para o desenvolvimento do raciocínio geográfico.

Silva (2016) em sua tese de doutorado com escolas públicas, também no estado de Goiás, demonstra precariedade nas maiorias das escolas nas quais estudou. Contudo, existe uma tentativa de precarização das condições materiais das instituições para desqualificar a escola pública em prol da privatização, pois há o interesse de grandes setores privados que apoiam tal iniciativa. Assim, no estado goiano há um aumento de estímulo às escolas militares com forte apoio financeiro para essas instituições. Além disso, há uma tentativa no projeto de terceirizar os serviços na escola pública, visando à diminuição de gastos com a educação. Dessa forma, o estado de Goiás tem implementado escolas militares como modelos para dizer que a escola pública, com serviços públicos, investimentos públicos, gestão democrática, não dá certo. Para tanto, o autor constatou que para se ter bons índices em avaliações externas alguns governos do estado de Goiás têm investido mais dinheiro nas militares, fazem processo de seleção de alunos, excluem os alunos considerados indisciplinados, treinam as avaliações que servem de padrão para mensurar o sucesso escolar. 
Em consequência disso, o que tem havido é a tentativa de fragilizar cada vez mais a escola pública, de extrema importância para um país como o Brasil de desigualdades sociais extremas. Diante de tal situação, há necessidade de resistência dos professores na escola pública, pois, de acordo com Lima et al (2019, p. 06), “[...] é possível a partir de medidas simples e baixo custo operacional realizar uma diversidade metodológica maior, visando um melhor aproveitamento do processo de ensino-aprendizagem". Tais medidas de custo operacional são necessárias para um maior investimento na formação inicial e continuada de professores. Nesse sentido, na próxima seção será realizada uma breve reflexão sobre a formação docente.

\section{A FORMAÇÃO DE PROFESSORES NO BRASIL}

A formação de professores no Brasil passa por constantes mudanças, estas implicam em consequências para a atuação docente na escola básica. Hoje, com a complexidade do mundo contemporâneo, há uma intensificação das exigências para que os professores exerçam suas atividades profissionais. Tais exigências são ainda mais marcantes a partir da década de 1990, pois se tem requerido maior e melhor busca pela formação de qualidade do professor para atuar na Educação Básica.

A formação do professor no Brasil, assim como diz Cunha (2010), é complexa. Isso se deve a questões que abarcam, além da prática educativa na escola, questões econômicas, políticas e sociais. De acordo com Pires (2012), as estratégias pedagógicas por meio dos procedimentos teórico-metodológicos nos moldes tradicionais liberais são mais comuns do que imaginamos. Concorda-se com a autora que isso é um fato, pois diversas condições fazem com que isso ocorra, dentre elas, lacunas de formação. A pesquisa desta autora sobre a atuação dos professores nas escolas públicas no Estado de Goiás, Brasil, mostrou que a formação inicial pouco contribuiu para a atuação dos docentes por ela estudados. Dessa forma, os professores de Geografia têm saído das instituições de ensino superior com lacunas de formação. Somam-se a isto as condições de carreira e estrutural que o docente poderá encontrar na inserção nos espaços escolares.

Contudo, "trazer os conhecimentos adquiridos nos cursos de formação inicial para a sala de aula da escola ainda é um desafio para os professores de Geografia” (PIRES, 2012, p. 25). Isso porque as pesquisas nos últimos anos têm demonstrado a pouca procura dos professores pela formação. Dessa forma, os professores devem compreender que esse 
processo ocorre na vida toda e é indispensável continuar os estudos. Logo, a formação inicial e continuada são etapas indissociáveis. No estudo de Pires (2013), a autora coloca como as principais justificativas dadas pelos docentes para não continuarem a estudar são as faltas: de incentivo, de tempo, de ganho salarial e de certificação. No entanto, ressalva-se que essa questão é complexa e, por isso, não se quer culpar o professor pela ausência da formação tampouco pelo estímulo à formação. Logo, deve-se levar em conta o contexto de incerteza do mundo contemporâneo e de crises do modelo de sociedade construídos sob a ótica da competitividade e do consumo (MORIN, 2003).

A formação de professores no Brasil é extremamente importante para a atuação dos professores em sala de aula, pois pode instrumentalizá-los a desempenhar seu trabalho de forma crítica e reflexiva. Contudo, ela é complexa e envolve um conjunto de fatores tanto de ordem interna em sala de aula bem como de fatores que extrapolam os elementos en dógenos. Nesse sentido, para promover a formação dos professores e a construção de sua identidade, destaca-se a necessidade de desenvolver nesses educadores habilidades de saberes articulados a suas práticas educativas, como: saberes da experiência, saberes dos conhecimentos específicos disciplinares, saberes pedagógicos, saberes didáticos e, por fim, saberes do contexto dos sujeitos envolvidos nos processos de ensino-aprendizagem (PIMENTA, 1999).

Diante disso, parte-se da premissa que existe uma base de conhecimentos necessários a serem mobilizados pelos professores para a construção dos conceitos na escola. Alguns autores, como Chevallard (1991) trabalham com a ideia de transposição didática como sendo um conjunto de transformações que um saber precisa passar para ser ensinado. Neste estudo, trabalhou-se com a categoria conhecimento pedagógico do conteúdo de Shulman (2014), que é uma base necessária para a atuação dos professores em sala de aula, como o conhecimento pedagógico, o contexto do aluno e a disciplina na qual atua. Nessa perspectiva, o professor de Geografia, para poder desenvolver o raciocínio geográfico, necessita realizar tal articulação entre esses os saberes citados.

Sendo assim, o professor de Geografia pode se apropriar do conhecimento pedagógico do conteúdo como uma possibilidade na prática educativa nas escolas. Não obstante, para que haja realmente o desenvolvimento do raciocínio geográfico, esse trabalho deve estar norteado nos conceitos espaço, território, lugar, paisagem, região, princípios lógicos, localização, delimitação, extensão, conexão, rede, escala, dentre outros.

O raciocínio geográfico desenvolvido junto com o aluno na escola, por meio do ensino de Geografia, não é o mesmo que o pensamento geográfico da Geografia acadêmica realizado 
na universidade, mas tem algo em comum porque as duas precisam utilizar os conceitos da Geografia enquanto ciência para caracterizar-se como saber-geográfico. Assim, na Geografia Escolar, os alunos não criam as teorias acadêmicas, mas se apropriam dos conceitos científicos para a aprendizagem, desenvolvendo-se no entendimento e na atuação quanto ao espaço geográfico. Contudo, o professor de Geografia poderá encontrar na sua prática educativa desafios para o desenvolvimento do raciocínio geográfico como foi discutido durante as seções anteriores.

Portanto, há desafios para o desenvolvimento do raciocínio geográfico como: influência das políticas neoliberais, problemas nas estruturas das escolas e formação de professores. Dessa forma, é importante que o professor de Geografia continue investindo na sua formação para que possa ter a capacidade de ser crítico-reflexivo. E, assim, possa ter também ter a capacidade de identificar percalços que prejudicam seu trabalho pedagógico, canalizando forças que possam ressignificar e elaborar estratégias de resistências para cumprir o seu papel social de formar o aluno para interpretar as práticas espaciais e atuar nelas.

\section{CONSIDERAÇÕES FINAIS}

Neste estudo, discutiram-se alguns desafios que podem influenciar as estratégias pedagógicas dos professores de Geografia no desenvolvimento do raciocínio geográfico na Educação Básica, como: projetos neoliberais, condições estruturais das instituições educacionais e formação de professores.

Partiu-se da definição de raciocínio geográfico ser um processo cognitivo desenvolvido junto ao aluno na Educação Básica, por meio da apropriação dos conceitos espaço, território, paisagem, princípios lógicos, delimitação, extensão, conexão, distribuição, rede, escala, localização - articulados nas estratégias pedagógicas do professor de Geografia. Tal premissa ainda não é consensual, mas pesquisadores na área de ensino de Geografia vêm a indicar tal cognição como potencial ao desenvolvimento dos alunos enquanto possibilidades de mobilização de habilidades espaciais.

O raciocínio geográfico é um processo cognitivo potencial na escolarização dos estudantes na Educação Básica, mas o seu desenvolvimento perpassa por desafios e possibilidades, no qual neste estudo o foco foi se discutir alguns desafios, como projetos neoliberais, condições estruturais das instituições educacionais e formação de professores. Por outro lado, cabe aos professores reconhecerem a existência de tais desafios nas suas práticas 
educativas, mas devem buscar alternativas de resistências para o desenvolvimento dos escolares.

Constatou-se que as políticas neoliberais têm sido um dos desafios para o desenvolvimento do raciocínio geográfico, pois as reformas globais na educação ocorridas pós-década de 1990 têm influenciado os direcionamentos dos caminhos da educação pública no Brasil. Isso tem se constatado, por exemplo, com a lei 13.415/2017, da reforma do Ensino Médio, a qual expressa somente às disciplinas de Língua Portuguesa e Matemática como obrigatórias e as demais enquanto itinerários formativos. Logo, direcionam-se os processos formativos em demasia para o ensino técnico em detrimento do desenvolvimento humano integral já que o teor da lei expõe o anseio do ensino técnico. Não é o desejo de "demonizar" o ensino técnico, mas que ele deve estar ancorado aos demais campos do conhecimento em perspectiva integral do aluno.

As condições estruturais, apesar de não ser o único determinante no desenvolvimento no raciocínio geográfico, exerce influência na organização do trabalho docente. Isso se concretiza no sentido de que, quanto maior e melhor forem às condições físicas das instituições, o professor poderá inovar ou ressignificar estratégias pedagógicas, por conseguinte, amplia-se a possibilidade de haver o desenvolvimento do raciocínio geográfico. Caso contrário, ele terá dificuldades, pois os processos educativos são complexos e precisa-se de condições para que isso aconteça de forma mais efetiva.

Por fim, problemas na formação dos professores também é um desafio que prejudica o desenvolvimento do raciocínio geográfico, haja vista que para desenvolvê-lo o processo precisa mobilizar o conhecimento pedagógico do conteúdo, que se constitui da articulação indissociável dos conhecimentos didático-pedagógicos, do contexto de interesse do aluno e dos fundamentos da ciência de que se orienta a disciplina escolar. Primeiro, os conhecimentos didático-pedagógicos são importantes, pois são eles que dão viabilidade ao docente para compreender processos cognitivos, afetivos e de estratégias pedagógicas. Segundo, os conhecimentos de contexto do aluno devem servir como recurso para desenvolver as capacidades mentais do estudante em identificar, analisar, interpretar e, consequentemente, mudar a sua relação com o espaço geográfico. Por último, o raciocínio geográfico só acontece se houver a apropriação e a mobilização dos conceitos (espaço, território, lugar, região, paisagem) e dos princípios lógicos (localização, delimitação, extensão, conexão, rede, escala, arranjo, descrição, dentre outros). Cabe ressaltar que tais fundamentos não devem ser ensinados; não precisam aparecer todos em determinados problemas ou ao se trabalhar 
determinado conteúdo; não precisa haver uma hierarquia; mas, quando se for trabalhar determinado conteúdo ou resolver uma situação problema qualquer, obrigatoriamente, devem estar presentes os fundamentos.

Portanto, a prática educativa dos professores de Geografia pode apresentar desafios para que se possa desenvolver o raciocínio geográfico no aluno, mas tais desafios devem ser identificados pelos docentes. E, a partir dessa identificação, o docente pode traçar estratégias pedagógicas para desenvolver o raciocínio geográfico respeitando as limitações de contexto, da escola, do público discente e da sua própria formação enquanto sujeito histórico-cultural.

\section{REFERÊNCIAS}

ALEXANDER, Robin. Visiones sobre la educación, caminos de reforma. Santiago: Universidad Gabriela Mistral, 2012.

Education, Culture and Cognition: intervening for growth International Association for Cognitive Education and Psychology. In: International Conference, 10th, 2005. Durham. Annals...Durham-UK: University of Durham - IACEP, 2005, 21 p.

BRASIL. Ministério da Educação. Parâmetros Curriculares Nacionais: terceiro e quarto ciclos do ensino fundamental. Secretaria de Educação Básica. Brasília: MEC/SEB, 1998.

Ministério da Educação. Brasília. Base Nacional Comum Curricular. Secretaria de Educação Básica. Brasília: MEC/SEB, 2017.

LDB 9.394/96. Lei de Diretrizes e Bases da Educação Nacional, 1996. Disponível em http:http://www.planalto.gov.br/ccivil_03/LEIS/L9394.htm. Acesso em 11 de outubro de 2018.

CAVALCANTI, Lana de Souza. O trabalho do professor de Geografia e tensões entre demandas da formação e do cotidiano escolar. In: ROQUE ASCENÇÃO, Valéria de Oliveira Roque et al (Org.). Conhecimentos da Geografia: percursos de formação docente e práticas na sala de aula. Belo Horizonte: IGC, 2017.

$2013 \mathrm{a}$.

.Geografia, escola e construção de conhecimentos. 18 ed. Campinas: Papirus,

Geografia Escolar e a busca de abordagens teórico/práticas para realizar sua relevância social. In: SILVA, Eunice Isaias da Silva; PIRES, Lucineide Mendes. Desafios da didática de Geografia. Goiânia: Editora da Puc Goiás, 2013 b.

O Ensino de Geografia na escola. Campinas, SP: Papirus, 2012. 
.A Geografia e a realidade escolar contemporânea: avanços, caminhos, alternativas. In: I seminário nacional: Currículo em movimento-Perspectivas Atuais, 2010, Belo Horizonte. Anais... Belo Horizonte:MG, 2010. p. 1-13.

CUNHA, Maria Isabel da. Lugares de formação: tensões entre a academia e o trabalho docente. In: DALBEM, Ângela Imaculada Loureiro de Freitas et al. Convergências e tensões no campo da formação e do trabalho docente. Belo Horizonte-MG: Autêntica, 2010.

CHEVALLARD, Yves. La transposición didáctica: del saber sabio al saber enseñado. Buenos Aires-ARG: Aique, 1991.

FREIRE, Paulo. Pedagogia da Autonomia: saberes necessários à prática educativa. 52.ed. Rio de Janeiro: Paz e Terra, 2015.

FILIZOLA, Roberto. Didática da Geografia: proposições metodológicas e conteúdos entrelaçados com a avaliação. Curitiba-PR: Base Editorial, 2009.

GAUDIO, Rogata Soares Del et al. Ensino de Geografia e formação de professores: desafios e possibilidades na contemporaneidade. In: ASCENÇÃO, Valéria de Oliveira Roque et al (Org.). Conhecimentos da Geografia: percursos de formação docente e práticas na sala de aula. Belo Horizonte-MG: IGC, 2017.

HARVEY, David. .Condição pós-moderna: uma pesquisa sobre as origens da mudança cultural. Tradução de Adail Ubirajara Sobral. 25. ed. São Paulo: Edições Loyola, 2014.

KHAOULE, Anna Maria Kovacs; Souza, Vamilton Camilo de.Desafios atuais à formação de professores de Geografia. In: Silva, Eunice da; Pires, Lucineide Mendes (Org.). Desafios da didática de Geografia. Goiânia-GO: editora da Puc Goiás, 2013.

KAERCHER, Nestor André. Desafios e utopias no ensino de Geografia. In: Castrogiovanni, Antônio Carlos et al. Geografia em Sala de aula: práticas e reflexões. 5.ed. Porto Alegre: Editora da UFRGS, 2010.

LIBÂNEO, José Carlos. O dualismo perverso da escola pública brasileira: escola do conhecimento para os ricos, escola do acolhimento social para os pobres. Educação e Pesquisa, São Paulo, v. 38, n. 1, p. 13-28, 2012.

Didática. São Paulo: Cortez, 1994.

LIMA, Marineldo de Brito; SANTOS, Francílio de Amorim dos; SANTOS, Cícero Almeida dos. Proposta metodológica voltada ao ensino médio: aula de campo ao parque nacional de sete cidades. Revista Equador, Teresina-PI, v. 8, n. 1, p. 67-81, 2019.

LACOSTE, Yves. Geografia, isso serve, em primeiro para fazer a guerra. Tradução Maria Cecília França.19.ed. Campinas: Papirus, 2012.

MORIN, E.; CIURANA, R.; MOTTA, R. Educar na era planetária: O pensamento como método de aprendizagem pelo erro e incerteza humana. São Paulo: Cortez Editora, 2003. 
MORAES, Loçandra Borges de. Raciocínio geográfico, cartografia temática e ensino de cidade. Boletim Paulista de Geografia, São Paulo, v. 99, p. 312-331, 2018.

MOREIRA, Ruy. Pensar e ser em Geografia: ensaios de história, epistemologia e ontologia do espaço geográfico. 2.ed. São Paulo: Editora Contexto, 2015.

PONTUSCHKA, Níbia Nacib. Políticas públicas do ensino e da formação dos professores: construção de conhecimentos. In: ALBUQUERQUE, Maria Adailza Martins de; FERREIRA, Joseane Abílio de Sousa ( Org.). Formação, pesquisa e práticas docentes: reformas curriculares em questão. João Pessoa: Mídia, 2013.

PIRES, Lucineide Mendes. Da formação inicial ao exercício da profissão docente: entre desafios, perspectivas e práticas no cotidiano do professor de Geografia. Revista Brasileira de Educação em Geografia, Campinas, v. 2, n. 4, p. 15-39, 2013.

. Revisando os conceitos geográficos e sua abordagem no ensino. In: SILVA, Eunice Isaias da Silva; PIRES, Lucineide Mendes. Desafios da didática de Geografia. Goiânia: Editora da Puc Goiás, 2013.

PIMENTA, Selma Garrido. Formação de professores: identidade e saberes da docência. In: PIMENTA, Selma Garrido. (Org.). Saberes Pedagógicos e atividades docentes. São Paulo: Cortez Editora, 1999.

ROQUE ASCENÇÃO, Valéria de Oliveira Roque; VALADÃO, Roberto Célio. Professor de Geografia: entre o estudo do fenômeno e a interpretação da espacialidade do fenômeno.Scripta Nova. Revista Electrónica de Geografía y CienciasSociales, BarcelonaEspanha, v.18, n.496 (03), pp 1-14, 2014.

SAVIANI, Dermeval. Política educacional no Brasil após a Ditadura Militar. Revista HISTEDBR On-line, Campinas-SP, v. 18, n. 2, p. 291-304, 2018.

SILVA, Alexsander Batista. A Geografia do espaço escolar: jovem-aluno, práticas espaciais e aprendizagem geográfica. 2016. Tese ( Doutorado em Geografia), Instituto SocioambientalIESA, Universidade Federal de Goiânia, Goiânia, 2016.

SILVA, Patrícia Assis; ROQUE ASCENÇÃO, Valéria; VALADÃO, Roberto Célio. Por uma construção do raciocínio geográfico para além do pensamento espacial(SPATIAL THINKING). In: Colóquio da Rede Internacional Latino-americana de Pesquisadores da Didática em Geografia, 5, 2018, Pirenópolis-GO. Anais ... Goiânia: LEPEG, 2018.

SHULMAN, Lee S. Conhecimento e ensino:fundamentos para a nova reforma. Cadernos Cenpec, São Paulo, v. 4, n. 2, p. 196-229, 2014.

. Those who understand: Knowledge growth in teaching. Educational researcher, v. 15, Estados Unidos, n. 2, p. 4-14, 1986.

SANTOS, Milton. Por uma outra globalização: do pensamento único à consciência universal. 25.ed. Rio de Janeiro: Record, 2015. 
.Técnica, Espaço, Tempo: Globalização e Meio Técnico-científico-informacional. 5.ed. São Paulo: Editora da Universidade de São Paulo, 2008.

TARDIF, Maurice. Saberes Docentes e formação profissional. 14. ed. Petrópolis-RJ: Vozes, 2012.

VYGOTSKY, Lev Semenovich. A construção do pensamento e da linguagem. Tradução de Paulo Bezerra. 2. ed. São Paulo: Martins Fontes, 2009.

YOUNG, Michael. Para que servem as escolas?. Educação \& Sociedade, São Paulo, v. 28, n. $101,2007$. 